\title{
Temporomandibular Disorders and Fibromyalgia: A Narrative Review
}

\author{
Roberta Scarola ${ }^{1}$, Nicola Montemurro ${ }^{2}$, Elisabetta Ferrara ${ }^{3}$, Massimo Corsalini $^{4}$, llaria Converti ${ }^{5}$, Biagio Rapone ${ }^{6 *}$ \\ ${ }^{1}$ Department of Orthodontic Dentistry, University of Rome "Cattolica del Sacro Cuore," 00168 Rome, Italy; ${ }^{2}$ Department of \\ Translational Research and of New Surgical and Medical Technologies, University of Pisa, Pisa, Italy; ${ }^{3}$ Complex Operative Unit \\ of Odontostomatology, Chieti, Italy; ${ }^{4}$ Department of Medicine, "Aldo Moro" University of Bari, 70124 Bari, Italy; ${ }^{5}$ Department of \\ Emergency and Organ Transplantation, Division of Plastic and Reconstructive Surgery, "Aldo Moro" University of Bari, Bari, Italy; \\ ${ }^{6}$ Department of Basic Medical Sciences, Neurosciences and Sense Organs, "Aldo Moro" University of Bari, 70124 Bari, Italy
}

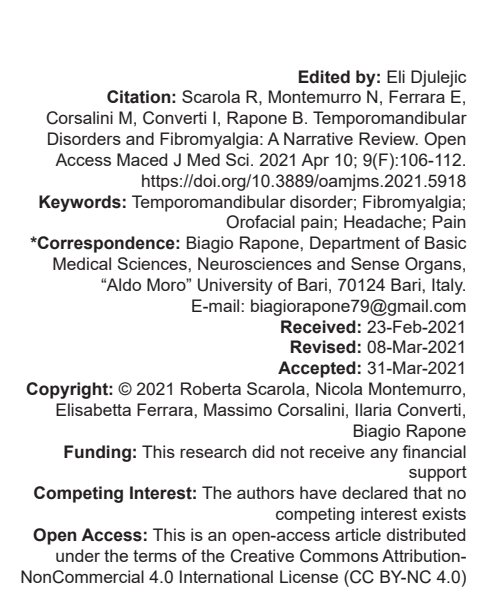

Abstract

Temporomandibular disorder (TMD) and fibromyalgia (FM) have some clinical characteristics in common, for instance the chronic evolution, the pathophysiology incompletely understood and a multifactorial genesis. The incidence and the relationship between TMD and FM patients are the aims of this review. A MEDLINE and PubMed search were performed for the key words "temporomandibular disorder" AND "fibromyalgia" from 2000 to present. A total of 19 papers were included in our review, accounting for 5449 patients. Ten studies, reporting a total of 4945 patients with TMD, showed that only $16.5 \%$ of these patients had diagnosis of FM, whereas 12 studies, reporting a total of 504 patients with FM, demonstrated that $77.0 \%$ of these patients had diagnosis of TMD. A comorbid relationship exists between TMD and FM. The complexity of both diseases shows the importance of a multimodal and interdisciplinary.

\section{Introduction}

Temporomandibular disorders (TMDs) describe a variety of dysfunctions and pain related to the masticatory system and characterized by craniofacial pain involving the joint, masticatory muscles, muscle innervations of the head and the neck, functional movement limitations of the mandible, clicking sounds, or grinding and clenching. TMD represents the major cause of non-dental pain in the orofacial region and the second most common musculoskeletal condition (after chronic low back pain) resulting in pain and disability. Although most common signs and symptoms of TMD are muscle pain in the head, neck, and noise, pain in the temporomandibular joint (TMJ), symptoms such as headache, facial and nape pain, dental pain, tinnitus, and dysgeusia can be present.

The research diagnostic criteria for TMD (RDC/ TMD) were introduced by Dworkin and LeResche in 1992 [1]. RDC/TMD has substantially contributed to TMD research by providing detailed standard instructions, comprising a dual-axis approach, and identified three different subtypes, which are TMJ disorders (join pain, arthralgia, and joint disorders), masticatory muscle disorders (muscle pain, contracture, and movement disorders), and headache [1]. Fibromyalgia (FM) is a chronic rheumatic syndrome characterized by bodywide musculoskeletal pain, asthenia, anxiety, and sleep impairments [2]. Diagnosis is confirmed after 3 months of widespread pain and tenderness in 11 of 18 musculoskeletal locations. Other symptoms reported in FM patients are chronic headache, stress, morning stiffness, fatigue, and mood disorders [3], [4]. These signs and symptoms are also frequently diagnosed as part of TMD.

TMD and FM have some clinical characteristics in common, for instance the chronic evolution, the pathophysiology incompletely understood, the serious physical and psychological impact, the shared predisposing factors, and a multifactorial genesis [2]. Pain-related TMD as also FM can impact on individual's daily activities, psychosocial functioning, and quality of life. Pain is determined by a complex interaction between 
mechanical, biological, and cognitive factors; however, there are in addition predisposing morphostructural (anatomical alterations) and psychoemotional (stress and anxiety) factors. The incidence and the relationship between TMD and FM patients are the aims of this review. We report the incidence and the clinical features of FM in patients with TMD as also the incidence and the clinical characteristics of TMD in patients with FM to better understand their relationship.

\section{Materials and Methods}

A MEDLINE and PubMed search were performed for the key words "temporomandibular disorder" AND "fibromyalgia" from 2000 to present. Only reports in English were used. Case reports, reviews, and series reporting animal studies were excluded from the study. Studies were also excluded if they did not report any clinical association data between TMD and FM or if they reported clinical studies in children. Eligibility assessment was performed independently in an unblinded standardized manner by two reviewers. Disagreements between reviewers were resolved by consensus. Collected data were used for the final analysis, whose endpoints were to evaluate the clinical association and relationship between TMD and FM, and vice versa. The flowchart for criteria and inclusion is presented in Figure 1.

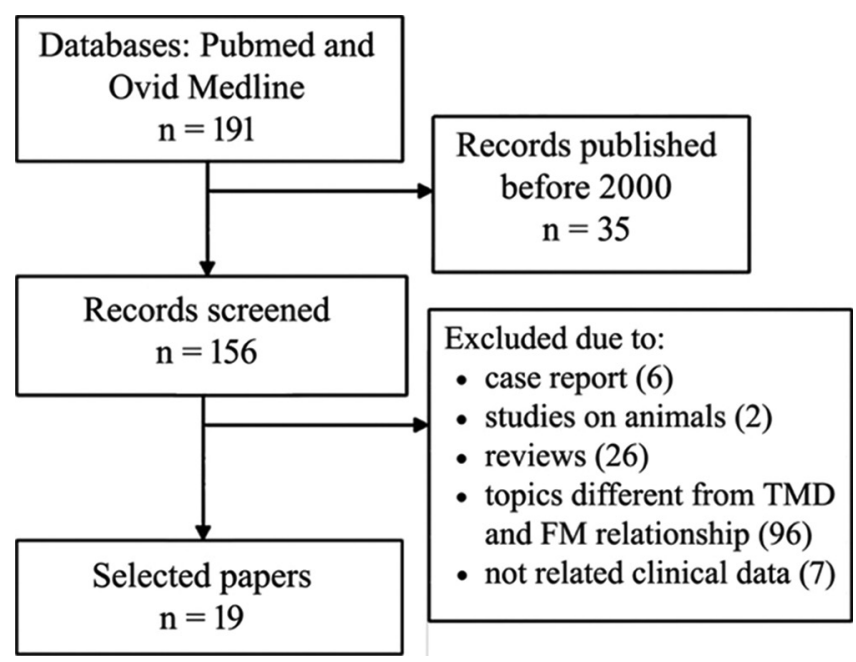

Figure 1: Flow diagram of the study selection

\section{Results}

The PubMed and Ovid Medline databases search yielded 156 records (Figure 1). Accordingly with the exclusion criteria, 137 records were discarded as follows: Case report (6), studies on animals (2), reviews
(26), topics different from clinical relationship between TMD and FM (96), and absence of related clinical data (7). A total of 19 papers were included in our review, accounting for 5449 patients [5], [6], [7], [8], [9], [10], [11], [12], [13], [14], [15], [16], [17], [18], [19], [20], [21], [22], [23], [24]. Ten studies (Group 1), reporting a total of 4945 patients ( $72 \%$ were female) with TMD, showed that only $16.5 \%$ of these patients had diagnosis of FM, whereas 12 studies (Group 2), reporting a total of 504 patients with FM (97.7\% were female), demonstrated that $77.0 \%$ of these patients had diagnosis of TMD. Tables 1 and 2 show all details.

Four different studies provided details about more specific symptoms in patients with TMD, reporting an overall value in pain during mandibular movements, orofacial pain at rest, and headache in $21.2 \%, 63.7 \%$, and $35.7 \%$ of patients, respectively [13], [15], [17], [24]. Similarly, five studies reported data regarding pain during mandibular movements, orofacial pain at rest, and headache in patients with $\mathrm{FM}$, which were $68.8 \%$, $66.5 \%$, and $81.2 \%$, respectively [8], [10], [11], [20], [21].

\section{Discussion}

TMD and FM are widely prevalent problems mostly in women but also in men and they include an array of musculoskeletal disorders from muscle contracture and myofascial pain syndrome to degenerative TMJ disease, even if widespread pain and tenderness on palpation are more common in patients with FM. FM is a rheumatic pain syndrome and it is often associated with sleep disturbance, fatigue, and often psychological distress [5]. It was reported that widespread pain, depression, and sleep disorders associated with FM may play a significant role in the chronicity of patients with TMD [5].

TMDs comprise several of pathologic conditions characterized by pain and tenderness in the TMJs and/or in the masticatory muscles and may reach the preauricular area [3].

These conditions also include functional movement limitations of the mandible, clicking sounds, or grinding and clenching. It occurs in young adults age 20-40 years, mostly in women [4], [6].

A high prevalence of TMDs in patients with FM suggests comorbidities and the need to consider the signs and symptoms of TMDs in the diagnosis of FM to improve pain management in these patients.

FM and TMD have signs and symptoms in common, aside from the pathophysiology and the biochemical mechanisms which cause them that are not so good understood until now.

Mechanisms that characterize chronic pain conditions in FM and TMDs are different. These 
Table 1: Data summary of the 10 included studies analyzed in the systematic review, reporting patients with TMD

\begin{tabular}{|c|c|c|c|c|c|c|c|c|}
\hline Authors & Year & Patients with TMD n & Age (mean) & $\mathrm{M} / \mathrm{F}$ & Patients with FM (\%) & Pain in mandibular movements (\%) & Orofacial pain (\%) & Headache (\%) \\
\hline Aaron et al. [6] & 2000 & 25 & 38 & - & $2(8)$ & - & - & - \\
\hline Manfredini et al. [18] & 2004 & 30 & - & - & $3(10)$ & - & - & - \\
\hline Leblebici et al. [16] & 2006 & 21 & 35.2 & $0 / 21$ & $11(52)$ & - & - & - \\
\hline Velly et al. [23] & 2010 & 572 & 35.5 & $69 / 572$ & $60(11)$ & - & - & - \\
\hline Hoffmann et al. [13] & 2011 & 1511 & 41 & $151 / 1360$ & $317(21)$ & $272(18)$ & - & $816(54)$ \\
\hline Eisenlohr-Moul et al. [9] & 2015 & 28 & 45 & $0 / 28$ & $11(39.3)$ & - & - & - \\
\hline Janal et al. [14] & 2016 & 125 & 39 & $0 / 125$ & $26(20.8)$ & - & $27(21.6)$ & - \\
\hline Losert-Bruggner et al. [17] & 2018 & 555 & 45 & $199 / 356$ & $351(63.2)$ & $167(30.1)$ & $457(82.3)$ & $262(47.2)$ \\
\hline Jussila et al. [15] & 2018 & 1962 & 46 & $912 / 1050$ & $26(1.3$ & - & - & $352(17.9)$ \\
\hline Vivaldi et al. [24] & 2018 & 116 & 43,5 & $39 / 77$ & $9(7.8)$ & - & $23(19.8)$ & $51(43.9)$ \\
\hline Total studies & - & 4945 & 42.8 & - & $816(16.5)$ & $439(21.2)$ & $507(63.7)$ & $1481(35.7)$ \\
\hline
\end{tabular}

Table 2: Data summary of the twelve included studies analyzed in the systematic review, reporting patients with FM

\begin{tabular}{|c|c|c|c|c|c|c|c|c|}
\hline Authors & Year & Patients with FM n & Age (mean) & M/F & Patients with TMD (\%) & Pain in mandibular movements (\%) & Orofacial pain (\%) & Headache \\
\hline Aaron et al. [6] & 2000 & 22 & 48.5 & - & $5(22.7)$ & - & - & - \\
\hline Olson et al. [19] & 2000 & 20 & - & $1 / 19$ & $12(60)$ & - & - & - \\
\hline Rhodus et al. [21] & 2003 & 67 & 47.6 & $0 / 67$ & $45(67.2)$ & $25(37.3)$ & - & - \\
\hline Manfredini et al. [18] & 2004 & 30 & - & - & $26(86.7)$ & - & - & - \\
\hline Leblebici et al. [16] & 2006 & 31 & 35.2 & $0 / 31$ & $25(80)$ & - & - & - \\
\hline Balasubramaniam et al. [7] & 2007 & 32 & 52.2 & $0 / 32$ & 19 (59.4) & - & $6(18.8 \%)$ & - \\
\hline Salvetti et al. [22] & 2007 & 93 & 50.1 & $5 / 88$ & 74 (79.6) & - & - & - \\
\hline Fraga et al. [10] & 2012 & 60 & 49.8 & $8 / 52$ & 49 (81.7) & $17(28.3)$ & 49 (81.7) & $58(97)$ \\
\hline Da Silva et al. [8] & 2012 & 25 & 47.7 & $1 / 24$ & $22(88)$ & $12(48)$ & - & $8(32)$ \\
\hline Pimentel et al. [20] & 2013 & 40 & 51.5 & $0 / 40$ & 31 (77.5) & - & $34(85)$ & - \\
\hline Gui et al. [12] & 2013 & 31 & 53 & $0 / 31$ & $27(87.1)$ & - & - & - \\
\hline Fujarra et al. [11] & 2016 & 53 & 50 & $0 / 53$ & $53(100)$ & $41(77.4)$ & $34(64.2)$ & $46(86.8)$ \\
\hline Total studies & - & 504 & 48.9 & - & $388(77.0)$ & 95 (68.8) & $123(66.5)$ & $112(81.2)$ \\
\hline
\end{tabular}

TMD: Temporomandibular disorder, FM: Fibromyalgia.

mechanisms are central sensitization, impairment of the descending pain inibitory system, neuronal convergence (which expalin the clinicla manifestations of chronic pain conditions), an higher bllod levels of serotonin (5-HT) [25] after exercising and lower blood flow in the masseter muscle. These claims are supported by various studies such as Guo et al. [26] and Okamoto et al. [27], [28].

Jackson and O'Farrell [24] demonstrated that oxidative stress can cause muscle damage and therefore be involved in many diseases like FM that affects the muscles [24].

In the past few years, several studies have demonstrated the presence of reactive oxygen species markers in FM, which would confirm their involvement in the pathophysiology of the disease [23], [24], [29].

Considerable indirect evidence seems to indicate that not only increased pain facilitation but also ineffective pain inhibition represents a predisposition for chronic pain. This view is supported by the fact that many chronic pain syndromes (e.g., FM, TMJ disorder, irritable bowel syndrome, headache, and chronic fatigue syndrome) are associated with hypersensitivity to painful stimuli and reduced endogenous pain inhibition [30].

The literature indicates that coexistence of FM and TMD with matrix metalloproteinases is high. Pain and tenderness in the masticatory muscles appear to be an important element in FM, so in some patients, it may be the leading complaint.

Chronic orofacial myalgia is characterized by muscle pain, tenderness, stiffness, and restricted range of mandibular movement. It can be localized and due to TMDs, or part of a generalized myalgia, for example, FM.
All the above evidence allows us to conclude that there is solid scientific support for the comorbid relationship between TMD and(1)headache, (2)chronic syndrome disease, and (3) FM. Nonetheless, in spite of the continuing advances in the pathophysiological mechanisms and the methodological designs, there are still some doubts regarding the nature of this comorbidity. The mentioned pain mechanisms, that is, central sensitization, impairment of the descending pain inhibitory system, and neuronal convergence, are more likely to explain the clinical manifestations of chronic pain conditions, rather than dissect specific underlying mechanism of chronic painful comorbidities.

Yet, the basic foundation supporting this review data is that TMD, headache, cervical spine disorder, and FM are distinct diseases. Nevertheless, such proposition has become fragile, considering the great similarity among the underlying mechanisms driven all of them, as already presented.

TMD is a local disorder and FM a generalized disorder, and there is less evidence of distress in those with TMD. TMD is a separate disorder from FM, but many patients with FM have TMD symptoms.

Plesh et al. [31] in their studies found that a small proportion of patients with TMD (18.4\%) also had FM, but most of those with FM $(75.0 \%)$ satisfied criteria for muscular (myofascial) TMD. Patients with FM had lower pain thresholds and more severe manifestations of all disease measures (e.g., pain, fatigue, sleep, etc.) compared to those with TMD. As might be predicted, they also had more painful body regions. Patients with FM also differed significantly from those with TMD in self-reported work ability and health assessment. The features that best differentiate FM from TMD 
are functional disability, reports of work difficulty, and general dissatisfaction with health.

Fraga et al. [10] and Fujarra et al. [11] reported a high incidence of TMD in patients with FM $(81.7 \%$ and $100 \%$, respectively), in particular with regard to pain during mandibular movements (28.3 and $77.4 \%$, respectively), orofacial pain $(81.7 \%$ and $64.2 \%$, respectively), and headache $(97 \%$ and $86.8 \%$, respectively). Similarly, Leblebici et al. [16], identifying two groups of patients (21 patients with TMD and 31 patients with FM), reported a high clinical associations between FM and TMD and vice versa. Balasubramaniam et al. [6] reported a high prevalence of TMD among FM patients too. Rhodus et al. [21] observing 67 patients diagnosed with FM (all women, mean age 47.6 years old), found a significant incidence of orofacial symptoms compared with control data, including xerostomia ( $70.9 \%$ vs. $5.7 \%)$, glossodynia (32.8\% vs. $1.1 \%)$, TMD $(67.2 \%$ vs. $20 \%)$, and dysphagia (37.3\% vs. $0.4 \%)$. Fujarra et al. [11] reported in their study that all FM patients had TMD symptoms; however, there were some differences between different groups depending on the onset of facial pain indicating that it is important to identify if facial pain or generalized body pain came first in the evaluation and treatment of the patients.

Although TMD and FM share common symptoms, including generalized pain sensitivity, sleep and concentration difficulties, bowel complaints, and headache; myofascial pain, including masticatory muscles, is a common finding in FM patients, whereas intra-articular TMJ disorders are not symptoms of FM.

Analyzing data in the literature about this issue, several studies [16] reported an involvement of the stomatognathic system in the course of FM syndrome similar to that characterizing TMDs, a heterogeneous group of pathologies affecting masticatory muscles, TMJs, and their associated structures [32]. Some studies showed that a high percentage of TMD patients report muscle tenderness and stiffness in other body regions that may be directly related to $\mathrm{FM}$, and a discrete prevalence rate of FM among TMD patients has been documented as well [33], [34], [35], [36], [37].

This last observation applies to patients with muscular TMD, in particular, and raises questions about the interpretation of myofascial face pain (MFP) in those cases, as this clinical condition shares several clinical features with FM. For example, it was suggested that MFP and FM might represent a different expression of the same condition [38]. They were considered as distinct disorders characterized by the same underlying pathophysiology [39]. MFP was suggested to be a regional expression of FM [34], and it was also hypothesized that MFP and FM represent the extremities of a clinical continuum [40].

Based on present knowledge, FM and MFP should be viewed as different pathologies for many reasons. First, MFP affects a restricted group of muscles, with a regional localized pain characterized by the presence of trigger points ( $\operatorname{TrPs})$, while $\mathrm{FM}$ is a systemic disease characterized by widespread pain and the presence of tender points (TePs). MFP typically arises as a response to an acute trauma or to a chronic overload of the stomatognathic system, as in the case of bruxism [41], while FM has an insidious onset with an incompletely known etiology, in which biochemical alterations, neuroendocrine abnormalities, and central sensitization mechanisms play an important role [42], [43], [44], [45]. Consequently, TrP characterizing MFP benefits from local treatments, while FM TeP requires systemic treatments [42], [46], [47].

Such observations raise questions about the interpretation of symptoms and signs of stomatognathic dysfunction in FM patients whose comprehension has a strong importance for a correct management of the patient with symptoms and signs involving the stomatognathic system.

Analyzing the prevalence of the different RDC/TMD diagnoses among patients with $F M$, it was observed that myofascial pain was present in $40.9 \%$, disk displacement in $29 \%$, and arthralgia, osteoarthritis, and osteoarthrosis in $71 \%$ of patients. Only some patients presented myofascial pain, while a high percentage presented inflammatory degenerative disorders. These results are in contrast with those observed by Plesh et al. [31] who found a prevalence of myofascial pain equal to $75 \%$. Pain and musculoskeletal rigidity characterizing FM can often involve the masseter muscles and the TMJs.

The overall prevalence of painful conditions (myofascial pain with or without limited opening, arthralgia and osteoarthrosis) was $62.4 \%(n=58)$ in patients with FM. These data agree with those from other studies [31], suggesting that orofacial pain is generally secondary to the onset of widespread musculoskeletal pain and that only in rare cases can TMD represent a first manifestation of chronic pain conditions.

Losert-Bruggner et al. [17] investigating the relationships between FM and craniomandibular dysfunction, reported that $63 \%$ of TMD patients fulfilled the diagnostic criteria of FM. Different studies reported that the presence of some conditions, such as migraine and FM, is associated with increased TMD intensity and duration. The complexity of both diseases shows the importance of a multimodal and interdisciplinary diagnosis. Salvetti et al. [22] provided data about the high rate of orofacial involvement in course of FM syndrome, suggesting that FM may sometimes represent an etiologic factor for TMD, and in particular, seem to have a worsening effect on the outcome of TMD. Pimentel et al. [20] showed that myofascial pain can be considered an important factor in FM diagnosis with a high coexistence of TMD. Thus, FM can be considered a predisposing factor for the development of TMD. 
The results in the study of Salvetti et al. [22] suggest that facial pain in patients with TeP could be an integrating part of $\mathrm{FM}$, while facial pain in patients with $\mathrm{TrP}$ is probably an expression of myofascial pain as described by Simons et al. [48]. Clinicians should know the peculiar characteristics of TeP and $\operatorname{TrP}$ [42], [49], [50], [51], [52], [53], [54], [55], [56] to make a differential diagnosis between localized and systemic muscle disorders, which may overlap in symptoms [57], and to detect the correct origin of facial pain. In fact, orofacial pain in FM patients with TePs seems to be related to the syndromic picture, while in those with TrPs, it seems to be an expression of MFP. In the case of TMD patients, some different suggestions can be drawn, since orofacial pain in the presence of $\mathrm{TrPs}$ is commonly related to MFP, but pain accompanied by the presence of TePs might represent a manifestation of a systemic disease, such as FM.

In view of such considerations, the dentist should know the basic principles useful to intercept patients whose orofacial symptoms could represent a manifestation of a systemic disease, since such patients have no benefit from local treatments [58] and need specific treatments involving the rheumatologist.

\section{Conclusions}

A comorbid relationship exists between TMD and FM. The lowering of prognosis of outcomes for TMD patients with FM (only $5 \%$ sustained remission after treatment) highlights the importance of recognizing whether the symptoms of a chronic TMD patient have origins in FM [5].

A comprehensive evaluation of patients with FM and TMD is necessary to identify specific treatments for orofacial complaints, pain in mandibular movements, and headache. Future studies, especially those with longitudinal design, should help clarify the role of orofacial complaints and TMJ disorders in patients with TMD and FM. To prevent and treat these chronic debilitating conditions, patients with TMD and FM need a careful multidisciplinary approach. To improve TMD and FM symptoms as also other existing comorbidities, it is necessary a more extensive interdisciplinary basic and clinical research and the development of outcomebased strategies to more effectively diagnose.

\section{References}

1. Dworkin SF, LeResche L. Research diagnostic criteria for temporomandibular disorders: Review, criteria, examinations and specifications, critique. J Craniomandib Disord.
1992;6(4):301-55.

PMid: 1298767

2. Ayouni I, Chebbi R, Hela Z, Dhidah M. Comorbidity between fibromyalgia and temporomandibular disorders: a systematic review. Oral Surg Oral Med Oral Pathol Oral Radiol. 2019;128(1):33-42. https://doi.org/10.1016/j.00oo.2019.02.023 PMid:30981530

3. McNeely ML, Olivo SA, Magee DJ. A systematic review of the effectiveness of physical therapy interventions for temporomandibular disorders. Phys Ther. 2006;86(5):710-25. https://doi.org/10.1093/ptj/86.5.710

PMid:16649894

4. Hilgenberg-Sydney PB, Kowacs PA, Conti PC. Somatosensoryevaluation in dysfunctional syndrome patients. J Oral Rehabil. 2016;43(2):89-95. https://doi.org/10.1111/ joor.12344 PMid:26337788

5. Fricton JR. The relationship of temporomandibular disorders and fibromyalgia: Implications for diagnosis and treatment. Curr Pain Headache Rep. 2004;8(5):355-63. https://doi.org/10.1007/ s11916-996-0008-0

PMid:15361319

6. Aaron LA, Burke MM, Buchwald D. Overlapping conditions among patients with chronic fatigue syndrome, fibromyalgia, and temporomandibular disorder. Arch Intern Med. 2000;160(2):2217. https://doi.org/10.1001/archinte.160.2.221

\section{PMid:10647761}

7. Balasubramaniam $R$, de Leeuw $R$, Zhu $H$, Nickerson RB, Okeson JP, Carlson CR. Prevalence of temporomandibular disorders in fibromyalgia and failed back syndrome patients: A blinded prospective comparison study. Oral Surg Oral Med Oral Pathol Oral Radiol Endod. 2007;104(2):20416. https://doi. org/10.1016/j.tripleo.2007.01.012

PMid: 17482850

8. Da Silva LA, Kazyiama HH, de Siqueira JT, Teixeira MJ, de Siqueira SR. High prevalence of orofacial complaints in patients with fibromyalgia: A case-control study. Oral Surg Oral Med Oral Pathol Oral Radiol. 2012;114(5):e29-34. https://doi. org/10.1016/j.000o.2012.04.001

PMid:22906580

9. Eisenlohr-Moul TA, Crofford LJ, Howard TW, Yepes JF, Carlson CR, de Leeuw R. Parasympathetic reactivity in fibromyalgia and temporomandibular disorder: Associations with sleep problems, symptom severity, and functional impairment. J Pain. 2015;16(3):247-57. https://doi.org/10.1016/j. jpain.2014.12.005

PMid:25542636

10. Fraga BP, Santos EB, Neto JP, Macieira JC, Quintans LJ Jr., Onofre AS, et al. Signs and symptoms of temporomandibular dysfunction in fibromyalgic patients. J Craniofac Surg. 2012;23(2):615-8. https://doi.org/10.1097/ scs.0b013e31824cd81a

PMid:22446432

11. Fujarra FJ, Kaziyama HH, Siqueira SR, Yeng LT, Camparis CM, Teixeira MJ, et al. Temporomandibular disorders in fibromyalgia patients: Are there different pain onset? Arq Neuropsiquiatr. 2016;74(3):195-200. https://doi. org/10.1590/0004-282×20160017

PMid:27050847

12. Gui MS, Pedroni CR, Aquino LM, Pimentel MJ, Alves MC, Rossini S, et al. Facial pain associated with fibromyalgia can be marked by abnormal neuromuscular control: A cross-sectional study. Phys Ther. 2013;93(8):1092-101. https://doi.org/10.2522/ ptj.20120338

PMid:23599350 
13. Hoffmann RG, Kotchen JM, Kotchen TA, Cowley T, Dasgupta M, Cowley AW Jr. Temporomandibular disorders and associated clinical comorbidities. Clin J Pain. 2011;27(3):268-74. https:// doi.org/10.1097/ajp.0b013e31820215f5 PMid:21178593

14. Janal MN, Raphael KG, Cook DB, Sirois DA, Nemelivsky L, Staud R. Thermal temporal summation and decay of aftersensations in temporomandibular myofascial pain patients with and without comorbid fibromyalgia. J Pain Res. 2016;9:641-52. https://doi.org/10.2147/jpr.s109038

PMid:27672341

15. Jussila $P$, Knuutila $J$, Salmela $S$, Näpänkangas $R$, Päkkilä J, Pirttiniemi $P$, et al. Association of risk factors with temporomandibular disorders in the Northern Finland Birth Cohort 1966. Acta Odontol Scand. 2018;76(7):525-9. https:// doi.org/10.1080/00016357.2018.1479769

PMid:29916756

16. Leblebici B, Pektaş ZO, Ortancil O, Hürcan EC, Bagis $S$, Akman MN. Coexistence of fibromyalgia, temporomandibular disorder, and masticatory myofascial pain syndromes. Rheumatol Int. 2007;27(6):541-4. https://doi.org/10.1007/ s00296-006-0251-z

PMid: 17096090

17. Losert-Bruggner $B$, Hülse $M$, Hülse R. Fibromyalgia in patients with chronic CCD and CMD-A retrospective study of 555 patients. Cranio. 2018;36(5):318-26. https://doi.org/10.1080/08 869634.2017.1334376

PMid:28580880

18. Manfredini D, Tognini F, Montagnani G, Bazzichi L, Bombardieri S, Bosco M. Comparison of masticatory dysfunction in temporomandibular disorders and fibromyalgia. Minerva Stomatol. 2004;53(11-12):641-50.

PMid:15894939

19. Olson GB, Savage S, Olson J. The effects of collagen hydrolysat on symptoms of chronic fibromyalgia and temporomandibular joint pain. Cranio. 2000;18(2):135-41. https://doi.org/10.1080/0 8869634.2000 .11746125

PMid:11202824

20. Pimentel MJ, Gui MS, de Aquino LM, Rizzatti-Barbosa CM Features of temporomandibular disorders in fibromyalgia syndrome. Cranio. 2013;31(1):40-5. https://doi.org/10.1179/ crn.2013.006

PMid:23461261

21. Rhodus NL, Fricton J, Carlson P, Messner R. Oral symptoms associated with fibromyalgia syndrome. J Rheumatol. 2003;30(8):1841-5. https://doi.org/10.1179/crn.2007.019 PMid:12913944.

22. Salvetti G, Manfredini D, Bazzichi L, Bosco M. Clinical features of the stomatognathic involvement in fibromyalgia syndrome: A comparison with temporomandibular disorders patients. Cranio. 2007;25(2):127-33.

PMid: 17508633

23. Drewes AM, Andreasen A, Schrøder HD, Høgsaa B, Jennum P. Pathology of skeletal muscle in fibromyalgia: A histo-immuno-chemical and ultrastructural study. $\mathrm{Br} \mathrm{J}$ Rheumatol. 1993;32(6):479-83. https://doi.org/10.1093/ rheumatology/32.6.479 PMid:8508284

24. Jackson MJ, O'Farrell S. Free radicals and muscle damage. $\mathrm{Br}$ Med Bull. 1993;49(3):630-41.

PMid:8221028

25. Dawson A. Experimental tooth clenching. A model for studying mechanisms of muscle pain. Swedish Dent J Suppl 2013;228:9-94
PMid:23631112

26. Guo W, Wang H, Zou S, Wei F, Dubner R, Ren K. Long lasting pain hypersensitivity following ligation of the tendon of the masseter muscle in rats: A model of myogenic orofacial pain. Mol Pain. 2010;6:40. https://doi.org/10.1186/1744-8069-6-40 PMid:20633279

27. Okamoto K, Kimura A, Donishi $T$, Imbe $H$, Nishie $Y$, Matsushita $\mathrm{H}$, et al. Contribution of peripheral $5-\mathrm{HT} 2 \mathrm{~A}$ or $\mathrm{HT} 3$ receptors to Fos expression in the trigeminal spinal nucleus produced by acute injury to the masseter muscle during persistent temporomandibular joint inflammation in rats. Neuroscience. 2006;143:597-606. https://doi.org/10.1016/j. neuroscience.2006.08.009

PMid:16979827

28. Okamoto K, Imbe H, Tashiro A, Kunabe S, Senba E. Blockade of peripheral $5 \mathrm{HT} 3$ receptor attenuates the formalin-induced nocifensive behavior in persistent temporomandibular joint inflammation of rats. Neurosci Lett. 2004;367(2):259-63. https:// doi.org/10.1016/j.neulet.2004.06.017

PMid:15331166

29. Bagis S, Tamer L, Sahin G, Bilgin R, Guler H, Ercan B, et al. Free radicals and antioxidants in primary fibromyalgia: An oxidative stress disorder? Rheumatol Int. 2005;25(3):188-90. https://doi.org/10.1007/s00296-003-0427-8

PMid: 14689230

30. Vivaldi D, Di Giosia M, Tchivileva IE, Jay GW, Slade GD, Lim PF Headache attributed to TMD is associated with the presence of comorbid bodily pain: A case-control study. Headache. 2018;58(10):1593-600. https://doi.org/10.1111/head.13404 PMid:30178880

31. Plesh O, Wolfe F, Lane N. The relationship between fibromyalgia and temporomandibular disorders: Prevalence and symptom severity. J Rheumatol. 1996;23(11):1948-52. PMid:8923373

32. McNeill C. Management of temporomandibular disorders: Concepts and con- troversies. J Prosth Dent. 1997;77(5):510-22. PMid:9151272

33. Eriksson PO, Lindman R, Stal P, Bengtsson A. Symptoms and signs of mandibular dysfunction in primary fibromyalgia syndrome (PSF) patients. Swed Dent J. 1988;12(4):141-9. PMid:3206353

34. Marbach JJ. Is myofascial face pain a regional expression of fibromyalgia? J Musc Pain. 1995;3():93-7.

35. Vollaro S, Michelotti A, Cimino R, Farella M, Martina $R$ Epidemiologic study of patients with craniomandibular disorders. Report of data and clinical findings. Minerva Stomatol. 2001;50()1-2:9-14

PMid:11378633

36. Perrini P, Montemurro N, Caniglia M, Lazzarotti G, Benedetto N Wrapping of intracranial aneurysms: Single-center series and systematic review of the literature. $\mathrm{Br} J$ Neurosurg. 2015;29(6):785-91. https://doi.org/10.3109/02688697.2015.107 1320

\section{PMid:26313119}

37. Montemurro N, Perrini P, Mangini V, Galli M, Papini A. The Y-shaped trabecular bone structure in the odontoid process of the axis: A CT scan study in 54 healthy subjects and biomechanical considerations. J Neurosurg Spine. 2019;2019:1-8. https://doi. org/10.3171/2018.9.spine18396 PMid:30717040

38. Simons DG. Fibrositis/fibromyalgia: A form of myofascial trigger points? Am J Med. 1986;81(3A):93-8.

PMid:3464215

39. Bennett RM. Confounding features of the fibromyalgia 
syndrome: A current perspective of differential diagnosis. $J$ Rheumatol. 1989;19:58-61.

\section{PMid:2691683}

40. Schochat $\mathrm{T}$, Croft $\mathrm{P}$, Raspe $\mathrm{H}$. The epidemiology of fibromyalgia. Workshop of the standing committee on epidemiology European league against rheumatism (EULAR), Bad Sackingen, 19-21 November 1992. Br J Rheumatol. 1994;33(8):783-6. https://doi. org/10.1093/rheumatology/33.8.783

\section{PMid:7914457}

41. Manfredini D, Cantini E, Romagnoli M, Bosco M. Prevalence of bruxism in patients with different research diagnostic criteria for temporomandibular disorders (RDC/TMD) diagnoses. J Craniomandib Pract. 2003;21(4):279-85. https://doi.org/10.108 0/08869634.2003.11746263

PMid:14620701

42. Gerwin RD. Classification, epidemiology, and natural history of myofascial pain syndrome. Curr Pain Headache Rep. 2001;5(5):412-20. https://doi.org/10.1007/s11916-001-0052-8

PMid:11560806

43. Corsalini M, Di Venere D, Sportelli P, Magazzino D, Ripa M, Cantatore $F$, et al. Evaluation of prosthetic quality and masticatory efficiency in patients with total removable prosthesis: Study of 12 cases. Oral Implantol. 2018;11:230-40.

44. Corsalini M, Di Venere D, Rapone B, Stefanachi G, Laforgia A, Pettini F. Evidence of signs and symptoms of craniomandibular disorders in fibromyalgia patients. Open Dent J. 2017;11:91-98. https://doi.org/10.2174/1874210601509010009 PMid:28357002

45. Adler GK, Manfredsdottir VF, Creskoff KW. Neuroendocrine abnormalities in fibromyalgia. Curr Pain Headache Rep. 2002;6(4):289-98. https://doi.org/10.1007/s11916-002-0050-5 PMid:12095464

46. Cimino R, Michelotti A, Stradi R, Farinaro C. Comparison of clinical and psychologic features of fibromyalgia and masticatory myofascial pain. J Orofac Pain. 1998;12(1):35-41. PMid:9656897

47. White KP, Harth M. Classification, epidemiology, and natural history of fibromyalgia. Curr Pain Headache Rep. 2001;5(4):320-9. PMid: 11403735

48. Simons DG, Travell JG, Simons LS. Travell and Simons Myofascial Pain and Dysfunction: The Trigger Point Manual. $2^{\text {nd }}$ ed. Baltimore: Williams and Wilkins Co.; 1999. https://doi. org/10.1016/s1098-7339(99)90123-2
49. Di Venere D, Nardi GM, Lacarbonara V, Laforgia A, Stefanachi G, Corsalini $\mathrm{M}$, et al. Early mandibular canine-lateral incisor transposition: Case report. Oral Implantol. 2017;10(2):181-9. https://doi.org/10.11138/orl/2017.10.2.181 PMid:29876043

50. Corsalini M, Di Venere D, Carossa M, Ripa M, Sportelli P, Cantatore $\mathrm{F}$, et al. Comparative clinical study between zirconium-ceramic and metal-ceramic fixed rehabilitations. Oral Implantol. 2018;11(3):150-60.

51. Schneider MJ. Tender points/fibromyalgia vs. trigger points/ myofascial pain syndrome: A need for clarity in terminology and differential diagnosis. J Manipulative Physiol Ther. 1995;18(6):398-406. PMid:7595112

52. Borg-Stein J, Stein J. Trigger points and tender points: One and the same? Does injection treatment help? Rheum Dis Clin North Am. 1996;22(2):305-22. https://doi.org/10.1016/ s0889-857x(05)70274-x PMid:8860801

53. Quaglia E, Moscufo L, Corsalini M, Coscia D, Sportelli P, Cantatore $\mathrm{F}$, et al. Polyamide vs silk sutures in the healing of postextraction sockets: A split mouth study. Oral Implantol. 2018;11(2):115-20. https://doi.org/10.1227/ neu.0b013e31827fcda3

54. Perrini P, Montemurro N, lannelli A. The contribution of Carlo Giacomini (1840-1898): The limbus Giacomini and beyond. Neurosurgery. 2013;72(3):475-81; discussion 481-2. PMid:23208067

55. Rapone B, Ferrara E, Converti I, Loverro M, Loverro MT, Gnoni A, et al. Exploring the role of Fusobacterium nucleatum in preterm birth: A narrative review. Open Access Maced J Med Sci. 2020;8(F):1-7. https://doi.org/10.3889/oamjms.2020.5409

56. Rapone B, Ferrara E, Montemurro N, Converti I, Loverro M, Loverro MT, et al. Oral microbiome and preterm birth: Correlation or coincidence? A narrative review. Open Access Maced J Med Sci. 2020;8(F):123-32. https://doi.org/10.3889/ oamjms.2020.4444

57. Alvarez DJ, Rockwell PG. Trigger points: Diagnosis and management. Am Fam Phys. 2002;65(4):653-60. PMid: 11871683

58. Raphael KG, Marbach JJ. Widespread pain and the effectiveness of oral splints in myofascial face pain. J Am Dent Assoc. 2001;132(3):305-16. https://doi.org/10.14219/jada. archive.2001.0173

PMid:11258087 